\title{
Factors influencing community pharmacists' recommendation of over-the-counter medications in four Vietnam cities
}

\author{
Van De $\operatorname{Tran}^{1,2 \star}$, Valeria Valeryevna Dorofeeva ${ }^{1}$, Ekaterina Efimovna \\ Loskutova ${ }^{1}$, Tatyana Petrovna Lagutkina ${ }^{1}$, Irina Vladimirovna Kosova ${ }^{1}$ \\ ${ }^{1}$ Department of Pharmaceutical Management and Economics, Peoples' Friendship University of Russia, Miklukho-Maklaya St, \\ 8k2, Moscow 117198, Russia, ${ }^{2}$ Faculty of Medicine, Can Tho University of Medicine and Pharmacy, Nguyen Van Cu St, 179, \\ Can Tho 902490, Vietnam
}

${ }^{*}$ For correspondence: Email: vandepro@gmail.com; Tel: +7-9851927647

Sent for review: 23 October 2018

Revised accepted: 13 January 2019

\begin{abstract}
Purpose: To determine the factors influencing the recommendation of over-the-counter (OTC) medicines to patients by community pharmacists in Vietnam.

Methods: The study was conducted at community pharmacies in Vietnam, from June 10 to October 30 , 2017. A final data set for analysis of 422 questionnaires was completed by community pharmacists from four different cities in Vietnam. Exploratory factor analysis was used to determine potential factors underlying a set of 20 questions related to the research topic. The association among the obtained factors and between the obtained factors and the pharmacists' demographics were determined by applying the Mann-Whitney U test and the Kruskal-Wallis test.

Results: Using factor analysis the current study identified five factors, accounting for $61.53 \%$ of the variance of the study, including customer, economic, professional, brand, and product. The product factor was found to have the most significant influence on pharmacists' recommendation of all the factors $(p<0.001)$.

Conclusion: There are five major factors influencing the decision-making process for the selection of OTC medicines by community pharmacists in Vietnam. These findings could be useful for pharmaceutical firms in the adaptation of product development and pharmaceutical marketing.
\end{abstract}

Keywords: Community pharmacist, Over-the-counter medicine, Exploratory factor analysis, Medicine recommendation

\begin{abstract}
This is an Open Access article that uses a funding model which does not charge readers or their institutions for access and distributed under the terms of the Creative Commons Attribution License (http://creativecommons.org/licenses/by/4.0) and the Budapest Open Access Initiative (http://www.budapestopenaccessinitiative.org/read), which permit unrestricted use, distribution, and reproduction in any medium, provided the original work is properly credited.
\end{abstract}

Tropical Journal of Pharmaceutical Research is indexed by Science Citation Index (SciSearch), Scopus, International Pharmaceutical Abstract, Chemical Abstracts, Embase, Index Copernicus, EBSCO, African Index Medicus, JournalSeek, Journal Citation Reports/Science Edition, Directory of Open Access Journals (DOAJ), African Journal Online, Bioline International, Open-J-Gate and Pharmacy Abstracts

\section{INTRODUCTION}

A community pharmacist is a professional healthcare provider who people can easily turn to, to receive advice for managing minor illnesses [1]. The number of community pharmacies in Vietnam is increasing rapidly. The number of pharmacy outlets reached 40,000 in $2011[2,3]$ and only after four years has increased to 1.4 times, accounting for 54,250 in 2015 [4]. Currently, pharmacists in Vietnam have a greater variety of over-the-counter (OTC) 
products to choose from when making recommendations for their patients. The OTC market has grown rapidly in recent years and is expected to continue to grow. The OTC sector is predicted to reach US $\$ 1.46$ billion and account for $26.0 \%$ of the total market value of sales in 2019 [5].

Self-medication by seeking healthcare from community pharmacies is a common practice among patients in many parts of the world [6], and is no exception for Vietnamese patients [7]. In Vietnam, patients are more likely to prefer community pharmacies than other health care systems for their medication [8]. More than $80 \%$ of people seek immediate community pharmacists when they have health-related problems, for medicine purchases or healthrelated advice [9], which makes community pharmacies the most preferred contact point among health care providers [2]. The reasons for this selection by patients may be related to the higher costs of other public health services [10].

Over-the-counter medications are being favored by current patients for self-administered medications, possibly due to their lax management policies [7]. Nearly $45 \%$ of the total number of patients in Vietnam, most often prefer to choose OTC medication for self-management of minor diseases, as soon as they have of symptoms [5]. This may lead to unsuitable use of OTC medicines among patients [8]. It is therefore required that the community pharmacist be more responsible for suggesting the appropriate drug for the patient from the variety of OTC drugs in the market, as well as providing necessary medication counseling to ensure the effective use of OTC medicines.

The decision-making of choosing OTC drugs by community pharmacists is nowadays receiving more concern from pharmaceutical policy makers and companies, because it not only directly affects the development of the OTC market [5], but also positively impacts the consumers' consumption of OTC drugs [11]. This decision by the community pharmacist can be influenced by a variety of factors, such as factors related to the product, patient and professional influences, according to a study by Hanna and Hughes, in Northern Ireland, in 2007 [12]. Another study by Kotecki in the United States, in 2002, showed that medical, social, and marketing influences were important factors influencing the choice of OTC drugs [13]. Many previous studies on this topic have been reported in different countries [12-15]. However, there are limited studies conducted in the context of Vietnam's OTC pharmaceutical market. The purpose of the study was to determine the factors influencing OTC medicine choice of pharmacists working at community pharmacies in Vietnam, using exploratory factor analysis.

\section{EXPERIMENTAL}

Based on the review of the literature of previous studies [12-17], a questionnaire was developed to suit Vietnam's pharmaceutical practice. The first section of the questionnaire consists of 20 questions related to factors affecting pharmacist's medication choice, divided into seven categories: product (three items), clinical (three items), brand reputation (two items), advertising (two items), external (four items), economic (three items), and patient influences (three items). Each item was rated by pharmacists based on a 5-point Likert scale from 1 (very disagree) to 5 (very agree). The second part of the questionnaire includes questions about the demographic profile of the pharmacist.

A cross-sectional study was conducted at community pharmacies in Vietnam, between June 10 and October 30, 2017. A total of 560 questionnaires were sent to pharmacists working in community pharmacies in four cities, namely, Hanoi, Da Nang, Ho Chi Minh City, and Can Tho. The results of the 422 completed questionnaires, with a response rate of $75.4 \%$, were included in the data analysis.

\section{Ethical approval}

The study followed the principles and guidelines of Declaration of Helsinki [18]. In addition, ethical approval was obtained from the Ethics Committee of Can Tho University of Medicine and Pharmacy, Can Tho, Vietnam (no. HE2017001) and from the Ethics Committee of Peoples' Friendship University of Russia (no. 1801), Moscow, Russia.

\section{Data analysis}

Analysis of data collected was conducted using SPSS software, version 22.0. The adequacy of the data for factor analysis was assessed by using the following rules: (1) a sample of participants with a size greater than 300 [19,20], (2) the Kaiser-Meyer-Olkin (KMO) measure of sampling adequacy with a minimum accepted value of 0.6 [20], and (3) Bartlett's Test of Sphericity with significance at $p<0.05$ [19]. Factor analysis was used to determine the number of potential factors underlying the scale structure using principal component analysis and varimax rotation method. Kaiser criterion or eigenvalues-greater-than-one criterion and 
Cattell's scree test are used to determine the optimal number of factors to retain. An item is considered to be significantly loaded on a factor if the absolute value of its factor loading on that factor is above 0.45 [21] and the difference between its loading on the primary factor and alternative factors (cross-loading) should be at least 0.2 [20].

The reliability of the tool was assessed using Cronbach's alpha for each subscale (factors) and the overall scale of all items. The alpha coefficient with a minimum value of 0.6 is considered acceptable as suggested in a similar study by Roins et al [17]. For checking the internal consistency of the scale, the item-total correlations were used. A value of greater than 0.3 indicated adequate consistency [22]. The Mann-Whitney $U$ test and Kruskal-Wallis test were used to examine the association between extracted factors, and also the association between extracted factors and demographic variables, on the basis of a comparison of mean for groups, with $p<0.05$ considered significant.

\section{RESULTS}

The demographic description of the study participants is shown in Table 1 . The majority of the participants in the study were women $(68.2$ $\%$ ), between 26 and 35 years of age (45.7\%), and with experience of 2 - 5 years in pharmacy practice $(43.4 \%)$. More than two thirds of them were assistant pharmacists.

A sample of 422 pharmacists was used for the present study, which was considered to be a good sample size. KMO coefficient reached a high value of 0.77 . The result of Bartlett's test $\left(x^{2}\right.$ = 2402.68; df = 190; $p<0.001$ ) was found significant. The results of this preliminary analysis suggested that the data set was appropriate for conducting factor analysis.

From the results of factor extraction, it was found that the 5 factors having eigenvalue greater than 1 were proposed to be retained (Figure 1). Scree Plot showed that the inflection point was in the position of the sixth factor, so the first five factors were recommended to be retained (shown in Figure 1). Thus, the five-factor solution is considered the most satisfactory for this study.

Results of a factor rotation indicated that all items loaded only on a single factor with their factor loading above 0.45. However, variables $Q_{1}, Q_{5}$, $Q_{13}$, having a difference of less than 0.2 between their primary and alternative factor loadings, were proposed to be removed from the original dataset. Then, the process of factor rotation with the new dataset of 17 items was repeated and the results obtained are presented in Table 2.

Table 1: Demographic profile of participating pharmacists

\begin{tabular}{lcc}
\hline Demographic & N & $\%$ \\
\hline Gender & & \\
$\quad$ Male & 134 & 31.8 \\
$\quad$ Female & 288 & 68.2 \\
Age group (years) & & \\
25 or less & 85 & 20.1 \\
26-35 & 193 & 45.7 \\
36-45 & 100 & 23.7 \\
46-55 & 24 & 5.7 \\
56-60 & 11 & 2.6 \\
>60 & 9 & 2.1 \\
Pharmacy education & & \\
Pharmacist (university level) & 136 & 32.2 \\
Assistant pharmacist (secondary & 286 & 67.8 \\
school level) & & \\
Position & & \\
Pharmacy manager & 91 & 21.6 \\
General employee & 331 & 78.4 \\
Pharmacy experience (years) & & \\
1 or less & 57 & 13.5 \\
2-5 & 183 & 43.4 \\
6-10 & 101 & 23.9 \\
11-20 & 53 & 12.6 \\
21-30 & 21 & 5.0 \\
$\quad$ 30 & 7 & 1.7 \\
\hline
\end{tabular}

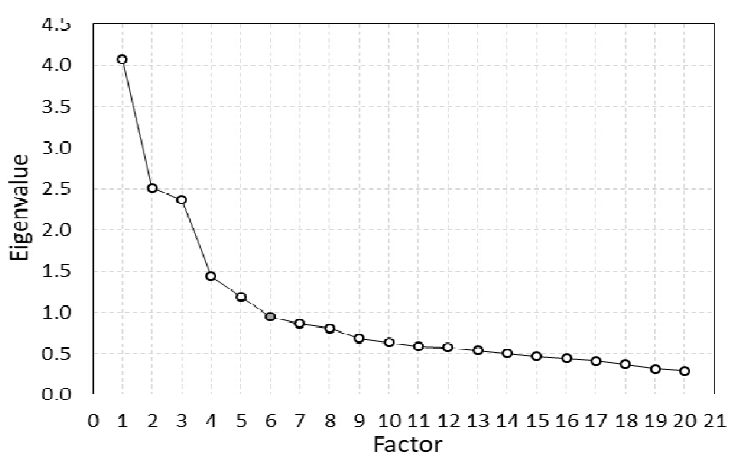

Figure 1: Screen plot for determining optimum factor solution. Key: $\circ=$ Eigenvalue

By using factor analysis, the study identified five factors, accounting for $61.53 \%$ of the variance of the study, which was considered as a good value of variance [19]. Each factor contained at least 3 items with factor loading above 0.45 and no presence of cross-loading. The item with higher factor loading that loaded on a factor was used to label that factor. Five extracted factors were named as follows: customer, economic, professional, brand, and product influences (Table 2, Figure 2).

The scale of this study had acceptable reliability with Cronbach's alpha value for the overall scale (0.75) and Cronbach's alpha value for each subscale (a range $0.69-0.75$, Table 3 ) 
Table 2: Factor loading of items from the result of factor rotation of final dataset

\begin{tabular}{|c|c|c|c|c|c|}
\hline \multirow{2}{*}{ Items } & \multicolumn{5}{|c|}{ Factor } \\
\hline & 1 & 2 & 3 & 4 & 5 \\
\hline \multicolumn{6}{|l|}{ Customer influences } \\
\hline$Q_{18}$ Patient characteristics & 0.76 & & & & \\
\hline$Q_{20} \quad$ Cost of product for patients & 0.71 & & & & \\
\hline$Q_{19}$ Ease of use and convenience to patient & 0.69 & & & & \\
\hline$Q_{4} \quad$ Product safety and efficacy for patient & 0.64 & & & & \\
\hline$Q_{14} \quad$ Customer feedback & 0.58 & & & & \\
\hline \multicolumn{6}{|l|}{ Economic influences } \\
\hline$Q_{16} \quad$ Financial pressure of excess stock & & 0.83 & & & \\
\hline$Q_{15}$ Profit from product & & 0.81 & & & \\
\hline$Q_{17} \quad$ Volume selling product & & 0.66 & & & \\
\hline \multicolumn{6}{|l|}{ Professional influences } \\
\hline$Q_{12}$ Recommendation of doctors & & & 0.80 & & \\
\hline$Q_{11}$ Recommendation of colleagues & & & 0.79 & & \\
\hline $\mathrm{Q}_{10}$ Product promotion by sales reps & & & 0.67 & & \\
\hline \multicolumn{6}{|l|}{ Brand influences } \\
\hline$Q_{8} \quad$ Confidence in manufacturer & & & & 0.79 & \\
\hline $\mathrm{Q}_{7}$ Company's reputation and brand popularity & & & & 0.78 & \\
\hline Q9 $\quad$ Medical advertising & & & & 0.75 & \\
\hline \multicolumn{6}{|l|}{ Product influences } \\
\hline$Q_{2}$ Combination of active ingredients & & & & & 0.84 \\
\hline$Q_{3} \quad$ Range of dosage forms & & & & & 0.77 \\
\hline$Q_{6} \quad$ Quick onset of action & & & & & 0.65 \\
\hline Eigenvalue & 2.47 & 2.28 & 1.92 & 1.91 & 1.88 \\
\hline Percentage of variance explained (\%) & 14.54 & 13.41 & 11.28 & 11.26 & 11.05 \\
\hline
\end{tabular}

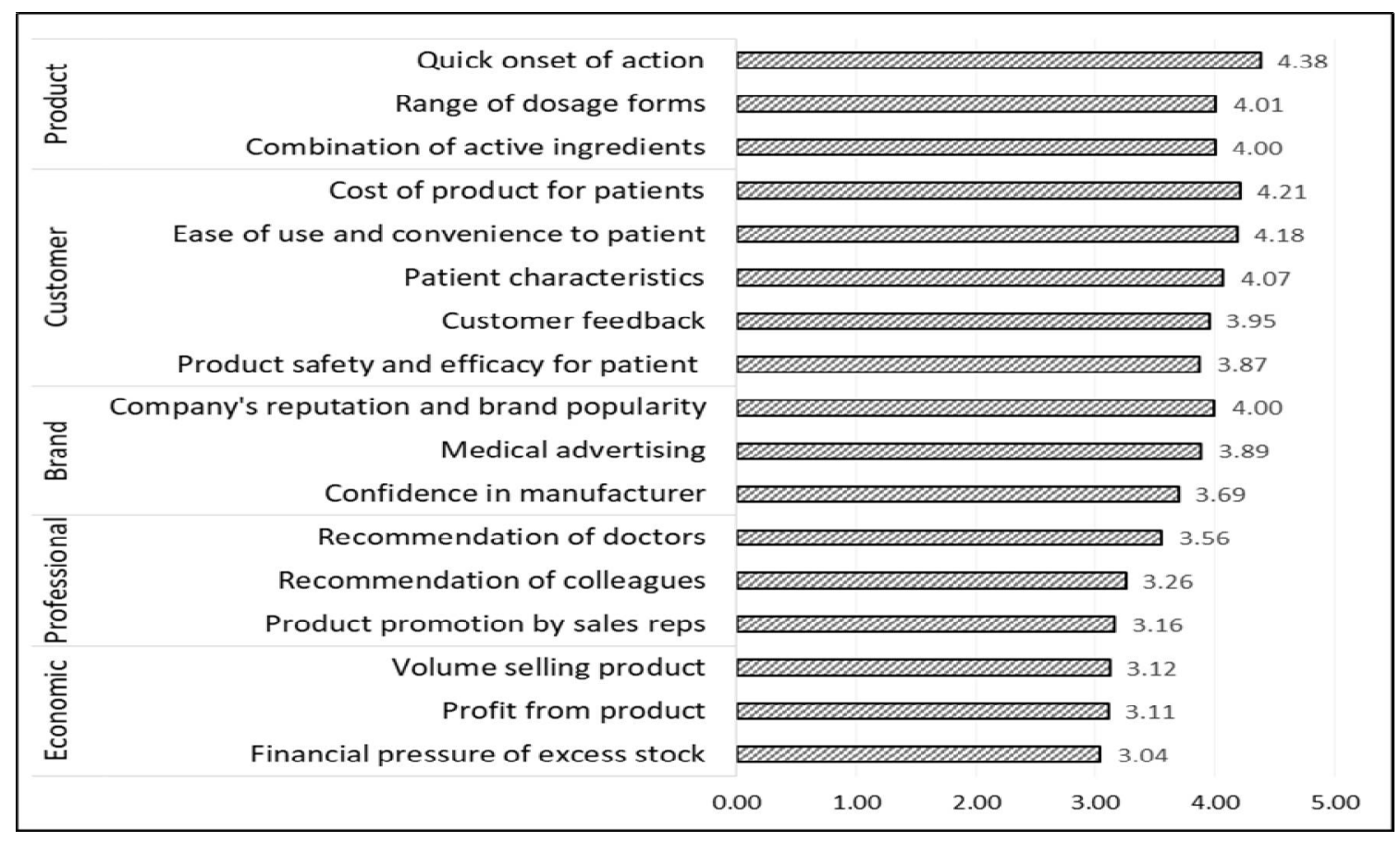

Figure 2: Distribution (mean) of factors influencing OTC products' selection

Additionally, the item-total correlation coefficient of each factor was greater than 0.4, which indicated that each factor contains items that are closely correlated with each other.

The result of Kruskal-Wallis test (Table 3) indicated that product influences (Mean $=4.13$ ) was the most important significant factor influencing the pharmacist's OTC drug selection practice, compared to other factors $(p<0.001)$. Next, customer (4.06) and brand (3.86) influences were also considered important. Professional and economic influence were found to be low impact factors. A description of distribution of mean for factors is presented in Figure 2. Consideration within product factors 
Table 3: Grand mean of factors, Kruskal-Wallis test and reliability test

\begin{tabular}{|c|c|c|c|c|c|}
\hline Factor & Mean (SD) & $P$-value & $\begin{array}{l}\text { Range of } \\
\text { item-total } \\
\text { correlation }\end{array}$ & $\begin{array}{c}\text { Cronbach's } \\
\text { alpha }\end{array}$ & $\begin{array}{c}\text { Overall } \\
\text { Cronbach's } \\
\text { alpha }\end{array}$ \\
\hline $\begin{array}{l}\text { Product } \\
\text { (3 items) }\end{array}$ & $4.13(0.64)$ & & $0.46-0.59$ & 0.69 & \\
\hline $\begin{array}{l}\text { Customer } \\
\text { (5 items) }\end{array}$ & $4.06(0.54)$ & & $0.41-0.55$ & 0.73 & \\
\hline $\begin{array}{l}\text { Brand } \\
\text { ( } 3 \text { items) }\end{array}$ & $3.86(0.63)$ & $<0.001$ & $0.48-0.52$ & 0.69 & 0.75 \\
\hline $\begin{array}{l}\text { Professional } \\
\text { ( } 3 \text { items) }\end{array}$ & $3.33(0.65)$ & & $0.44-0.62$ & 0.69 & \\
\hline $\begin{array}{l}\text { Economic } \\
\text { (3 items) }\end{array}$ & $3.09(0.82)$ & & $0.50-0.62$ & 0.75 & \\
\hline
\end{tabular}

showed OTC medication with quick onset of action (4.38) is best appreciated by pharmacists. Among the customer factors, cost of product for patients (4.21) and ease of use and convenience to patient (4.18) strongly influenced the decision of the pharmacist.

Table 4 presents the test results of relationship between five extracted factors and demographic profile of pharmacists. The findings showed that each factor has a statistically significant effect on the pharmacist groups with different demographic characteristics in the process of drug recommendations. Product factors significantly affect employee pharmacists rather than manager pharmacists $(p=0.020)$. Customer factor impact is significant for female pharmacists $(p=0.028)$ aged between 46 and 55 ( $p=0.001)$ than the other pharmacists. Brand factors directly affected pharmacist who were older than $61(p=0.006)$ and had university pharmacy education $(p=0.001)$. Economic factors had a positive effect on male pharmacist $(p=0.023)$ with secondary school pharmacy education $(p=0.040)$, age above $61(p<0.001)$ and experience over 30 years $(p=0.006)$. Professional factor was found to only affect pharmacists with university pharmacy education $(p=0.002)$.

Table 4: Association between five factors and demographic variables of pharmacists

\begin{tabular}{|c|c|c|c|c|c|}
\hline \multirow{2}{*}{ Demographic } & \multicolumn{5}{|c|}{ Mean (standard deviations) } \\
\hline & Product & Customer & Brand & Economic & Professional \\
\hline \multicolumn{6}{|l|}{ Gender } \\
\hline Male & $4.10(0.67)$ & $3.97(0.60)$ & $3.91(0.62)$ & $3.22(0.78)$ & $3.42(0.67)$ \\
\hline Female & $4.14(0.63)$ & $4.10(0.51)$ & $3.84(0.63)$ & $3.03(0.83)$ & $3.28(0.64)$ \\
\hline$P$-value & 0.666 & 0.028 & 0.267 & 0.023 & 0.070 \\
\hline \multicolumn{6}{|l|}{ Age group (years) } \\
\hline 25 or less & $4.05(0.61)$ & $3.99(0.57)$ & $3.92(0.53)$ & $3.00(0.87)$ & $3.31(0.60)$ \\
\hline $26-35$ & $4.15(0.63)$ & $3.99(0.51)$ & $3.74(0.65)$ & $2.92(0.68)$ & $3.25(0.58)$ \\
\hline $36-45$ & $4.19(0.65)$ & $4.20(0.57)$ & $3.99(0.64)$ & $3.29(0.94)$ & $3.39(0.76)$ \\
\hline $46-55$ & $4.26(0.69)$ & $4.34(0.42)$ & $3.90(0.66)$ & $3.58(0.69)$ & $3.57(0.71)$ \\
\hline $56-60$ & $3.88(0.75)$ & $3.89(0.65)$ & $4.00(0.42)$ & $3.45(0.89)$ & $3.55(0.76)$ \\
\hline$>61$ & $3.81(0.44)$ & $4.09(0.36)$ & $4.26(0.52)$ & $3.59(0.83)$ & $3.56(0.73)$ \\
\hline$P$-value & 0.061 & 0.001 & 0.006 & $<0.001$ & 0.219 \\
\hline \multicolumn{6}{|l|}{ Pharmacy education } \\
\hline University level & $4.10(0.61)$ & $4.06(0.47)$ & $4.00(0.58)$ & $2.99(0.83)$ & $3.44(0.66)$ \\
\hline Secondary school level & $4.14(0.65)$ & $4.06(0.58)$ & $3.79(0.64)$ & $3.14(0.82)$ & $3.27(0.64)$ \\
\hline$P$-value & 0.454 & 0.669 & 0.001 & 0.040 & 0.002 \\
\hline \multicolumn{6}{|l|}{ Position } \\
\hline Pharmacy manager & $4.03(0.58)$ & $4.00(0.54)$ & $3.95(0.61)$ & $3.18(.81)$ & $3.41(0.66)$ \\
\hline General employee & $4.16(0.65)$ & $4.07(0.54)$ & $3.84(0.63)$ & $3.07(.82)$ & $3.30(0.65)$ \\
\hline$P$-value & 0.020 & 0.233 & 0.113 & 0.227 & 0.141 \\
\hline \multicolumn{6}{|l|}{ Experience (years) } \\
\hline 1 or less & $4.05(0.66)$ & $4.07(0.52)$ & $3.81(0.59)$ & $3.02(0.85)$ & $3.32(0.62)$ \\
\hline $2-5$ & $4.18(0.63)$ & $3.99(0.57)$ & $3.81(0.66)$ & $2.94(0.79)$ & $3.31(0.59)$ \\
\hline $6-10$ & $4.15(0.60)$ & $4.08(0.56)$ & $3.85(0.59)$ & $3.21(0.72)$ & $3.23(0.63)$ \\
\hline $11-20$ & $4.09(0.69)$ & $4.22(0.48)$ & $3.99(0.64)$ & $3.27(0.95)$ & $3.38(0.83)$ \\
\hline $21-30$ & $4.00(0.70)$ & $4.10(0.47)$ & $3.97(0.55)$ & $3.44(0.88)$ & $3.73(0.63)$ \\
\hline$>30$ & $3.90(0.66)$ & $4.11(0.34)$ & $4.43(0.42)$ & $3.48(0.88)$ & $3.52(0.84)$ \\
\hline$P$-value ${ }^{\star \pi}$ & 0.491 & 0.245 & 0.081 & 0.006 & 0.063 \\
\hline
\end{tabular}




\section{DISCUSSION}

In the current study, pharmacist decision-making is most strongly influenced by the product factor. Moreover, Mann-Whitney $U$ test for each pair of factors showed that the product influence had a statistically significant effect on the pharmacist's choice than the brand $(p<0.001)$, professional $(p<0.001)$, and economic influences $(p<0.001)$. This factor represents important influences that pharmaceutical companies need to pay attention to, in order to boost medicine sales.

Specifically, products with quick onset of action should be targeted by pharmaceutical manufacturing companies in the orientation of developing OTC products, and by pharmaceutical distribution companies to introduce strategic OTC drugs into the pharmacy market with focus on employee pharmacists.

Based on the Mann-Whitney $U$ test for pairs of factors, brand influences such as the company's brand, brand popularity, and medical advertising are also evaluated to affect the pharmacist than professional $(p<0.001)$ and economic influences $(p<0.001)$. It can be recommended that product promotion campaigns directed at community pharmacists aged 61 years or more and with university pharmacy education are needed to be carried out by pharmaceutical companies to increase the demand for OTC drugs. These results in the current study are similar to a study by Kotecki in 2002, which indicates that medical factors were most important influences on the OTC product recommendation by pharmacists in USA than social, and marketing factors [13]. Another similar study conducted by Roins et al found that product influence had a high impact on non-prescription analgesic choice by pharmacists in Great Britain than advertising, economic, and social factors [16]. In this study, three dimensions of product, brand and professional influences appeared with a lower value of alpha reliability as compared with the common recommended value of 0.7 proposed by many researchers (Table 3) [20]. However, their reliability can be accepted because its value is close to approximately 0.7 . Some authors make less rigorous suggestions that a value of above 0.6 is acceptable [17,23]. In addition, the variance of greater than $5 \%$ for these factors, was considered appropriate [24]. These extracted factors have item-total correlation coefficients greater than 0.4. Therefore, the reliability of these three dimensions is considered as acceptable in the present study.

\section{Limitations of the study}

This study conducted a survey of community pharmacists who were working at community pharmacies in four big cities without considering the viewpoints of community pharmacists in other cities in Vietnam on their preference of drug choices. In future, this research is expected to expand to more cities and focus more on small cities and rural areas.

\section{CONCLUSION}

In the current study, five basic factors: customer, economic, professional, brand, product have been found to influence the pharmacist's choice of medicine. In particular, the decision-making process of Vietnamese community pharmacists is most significantly influenced by the product factor and least influenced by the economic factor. The study suggests that pharmaceutical manufacturers and distributors should be more concerned about the optimization of the properties of their product and choose to distribute products with appropriate features. In tandem, there is also a requirement for developing proper marketing campaigns to increase the attractiveness of OTC drugs to pharmacists when choosing medicine. The results of the study may be useful for pharmacy policy-makers and educators in enhancing their understanding of what factors influence the pharmacist's choice of OTC, as well as in improving and developing pharmacy education programs and undergraduate courses.

\section{DECLARATIONS}

\section{Acknowledgement}

The authors are grateful to the members of Department of Pharmaceutical Management and Economics in Peoples' Friendship University of Russia and community pharmacists in Vietnam for their cooperation. The study was part of the PharmD dissertation of VD Tran in the Peoples' Friendship University of Russia, Russia and was funded by the authors.

\section{Conflict of Interest}

No conflict of interest associated with this work.

\section{Contribution of Authors}

The authors declare that this work was done by the authors named in this article and all liabilities pertaining to claims relating to the content of this article will be borne by them.

Trop J Pharm Res, February 2019; 18(2): 426 


\section{REFERENCES}

1. McMillan SS, Thangarajah $T$, Anderson C, Kelly F. Pharmacy student decision making in over-the-counter medicine supply: A critical incident study. Res Soc Adm Pharm 2018; 14: 749-757.

2. Nguyen TA, Vitry A, Roughead EE. Pharmaceutical policy in Vietnam. In: Babar ZUD, editor. Pharmaceutical policy in countries with developing healthcare systems. Cham: Springer International Publishing; 2017; pp 7594.

3. Minh PD, Huong DT, Byrkit R, Murray M. Strengthening pharmacy practice in Vietnam: Findings of a training intervention study. Trop Med Int Heal 2013; 18: 426434.

4. Angelino A, Khanh DT, Ha NA, Pham T. Pharmaceutical industry in Vietnam: Sluggish sector in a growing market. Int J Environ Res Public Health 2017; 14: 976.

5. Business Monitor International. Vietnam pharmaceuticals \& healthcare report Q4 2010. London: Business Monitor International Ltd.; 2010.

6. Duong DV, Binns CW, Le TV. Availability of antibiotics as over-the-counter drugs in pharmacies: $A$ threat to public health in Vietnam. Trop Med Int Health 1997; 2: 11331139.

7. Australian Government Austrade, Australia Unlimited. Vietnam health supplements market overview. Australian Trade Commission; 2014.

8. Thuan NTB, Lofgren C, Lindholm L, Chuc NTK. Choice of healthcare provider following reform in Vietnam. BMC Health Serv Res 2008; 8: 162.

9. Chalker J, Chuc NTK, Falkenberg T, Tomson G. Private pharmacies in Hanoi, Vietnam: A randomized trial of a 2-year multi-component intervention on knowledge and stated practice regarding ARI, STD and antibiotic/steroid requests. Trop Med Int Health 2002; 7: 803-810.

10. Nga DTT, Chuc NTK, Hoa NP, Hoa NQ, Nguyen NTT, Loan HT, Toan TK, Phuc HD, Horby P, Yen NV et al. Antibiotic sales in rural and urban pharmacies in Northern Vietnam: An observational study. BMC Pharmacol Toxicol 2014; 15: 6 .

11. Ricks J, Mardanov I. The effect of pharmacists on drug purchasing behavior of price-sensitive consumers. J Med Mark 2012; 12: 177-187.
12. Hanna LA, Hughes CM. 'First, Do No Harm': Factors that influence pharmacists making decisions about over-thecounter medication. Drug Saf 2010; 33: 245-255.

13. Kotecki JE. Factors related to pharmacists' over-thecounter recommendations. J Community Health 2002; 27: 291-306.

14. Kennedy E, Moody M. An investigation of the factors affecting community pharmacists' selection of over the counter preparations. Pharm World Sci 2000; 22: 47-52.

15. Emmerton L, Benrimoj SI. Influences on pharmacists' stocking and recommendation of nonprescription products. J Pharm Mark Manage 1991; 5: 37-50.

16. Roins $S$, Benrimoj SI, Carroll P. Factors affecting pharmacists' choice of nonprescription analgesics. J Pharm Mark Manage 1994; 9: 3-18.

17. Roins S, Benrimoj SI, Carroll PR, Johnson LW. Factors used by pharmacists in the recommendation of the active ingredient(s) and brand of non-prescription analgesics for a simple, tension and migraine headache. Int J Pharm Pract 1998; 6: 196-206.

18. World Medical Association. World Medical Association Declaration of Helsinki: ethical principles for medical research involving human subjects. JAMA 2013; 310: 2191-2194.

19. Williams B, Onsman A, Brown T. Exploratory factor analysis: A five-step guide for novices. J Emerg Prim Heal Care 2010; 8: 1-13.

20. Howard MC. A review of exploratory factor analysis decisions and overview of current practices: What we are doing and how can we improve? Int J Hum Comput Interact 2016; 32: 51-62.

21. Tabachnick BG, Fidell LS. Using multivariate statistics. 5th ed. Boston: Allyn and Bacon; 2007.

22. Olatunji BO, Williams NL, Tolin DF, Abramowitz JS, Sawchuk CN, Lohr JM, Elwood LS. The Disgust Scale: Item analysis, factor structure, and suggestions for refinement. Psychol Assess 2007; 19: 281-297.

23. Hair JF, Black WC, Babin BJ, Anderson RE. Multivariate Data Analysis. 7th ed. New Jersey: Prentice Hall; 2010.

24. Vaz CJ, Pothiyil TD, George LS, Alex S, Pothiyil DI, Kamath $A$. Factors influencing examination anxiety among undergraduate nursing students: An exploratory factor analysis education section. J Clin Diagnostic Res 2018; 12: 16-19. 